\title{
Research progress in activation of phosphorus containing substances and remediation of heavy metal pollution in soil
}

\author{
Wang $\mathrm{Na}^{1,2,3,4}$ \\ ${ }^{1}$ Institute of Land Engineering and Technology, Shaanxi Provincial Land Engineering Construction Group Co., Ltd.; \\ ${ }^{2}$ Shaanxi Provincial Land Engineering Construction Group Co., Ltd.; \\ ${ }^{3}$ Key Laboratory of Degraded and Unused Land Consolidation Engineering, the Ministry of Natural Resources.; \\ ${ }^{4}$ Shaanxi Provincial Land Consolidation Engineering Technology Research Center
}

\begin{abstract}
The phenomenon of soil phosphorus deficiency in China is very serious, which limits the agricultural production in China. Low molecular weight organic acids and phosphorus solubilizing microorganisms are widely distributed in the soil, and can be used as activators to improve the content of phosphorus in the soil. With the rapid development of industry and agriculture in China, heavy metal pollution in the environment is becoming more and more serious. China is rich in phosphate rock resources, but the grade of phosphate rock is low and the utilization efficiency is not high. Using phosphate rock to deal with heavy metal pollution has been favored by environmental scholars. This paper analyzes the main composition and application of phosphate rock in China, the activation of phosphate rock powder, the remediation effect and mechanism of phosphate rock powder and activated phosphate rock powder on heavy metals in soil, providing theoretical basis for the scientific utilization of low-grade phosphate rock and the treatment of heavy metal pollution.
\end{abstract}

\section{Introduction}

Phosphorus plays an important role in the growth and development of animals and plants ${ }^{[1]}$. Phosphate rock is the only phosphate rock in the world, which is widely distributed. According to statistics, the global phosphorus reserves in 2011 have reached 65 billion tons, of which the reserves of China's phosphate rock are more than 4 billion tons. Phosphate rock is the general term of diphosphate minerals that can be used economically, and it is an important non renewable resource. There are many kinds of phosphate minerals in nature, but few of them are valuable for exploitation ${ }^{[2]}$. It has been reported that about $85 \%$ of the world's mined phosphate rock is used for phosphate fertilizer production ${ }^{[3]}$. With the rapid increase of population and the rapid development of agriculture, the demand for phosphate rock is increasing. Therefore, the exploitation and utilization of low-grade phosphate rock resources are more and more concerned, and the utilization of phosphate rock is also improving, including physical ${ }^{[4]}$, chemical ${ }^{[5]}$ and biological ${ }^{[6]}$ methods. Among them, the most effective method is chemical method, mainly the application of organic acid to the activator of phosphorite powder.

At present, with the rapid development of industry and agriculture, soil heavy metal pollution is becoming more and more serious. People gradually turn their attention to non-metallic minerals in the traditional heavy metal pollution treatment methods. These non-metallic minerals usually have large reserves and wide distribution. Some of them have good environmental compatibility ${ }^{[7]}$, and are ideal heavy metal repair materials. Some studies have shown that apatite has a special crystal chemical structure, which can adsorb and fix many heavy metal cations ${ }^{[2]}$. In recent years, the removal of heavy metals from aqueous solution and soil by phosphorus containing substances has achieved a little success ${ }^{[8-9]}$. Therefore, to explore the methods and ways of using phosphate ore to control heavy metal pollution in the environment can improve the economic and social benefits of phosphate ore application, and provide new ideas and methods for heavy metal pollution remediation.

\section{Phosphate rock composition and its application}

Phosphorus minerals are widely distributed in nature. However, there are few phosphate minerals that can be developed and utilized. According to their genesis, phosphate rocks can be divided into apatite and phosphorite. The representative phosphate minerals are shown in Table 1-1. The main chemical composition of apatite is calcium phosphate, in addition to iron, aluminum, silicon, magnesium, potassium and other trace elements. There are five kinds of fluorapatite, chlorapatite, hydroxyapatite, carboapatite and carbofluorapatite in nature. 
Table 1 representative phosphate minerals in nature ${ }^{[10]}$

\begin{tabular}{|c|c|}
\hline Mineral & Chemical Composition \\
\hline Fluorapatite & $\mathrm{Ca}_{5}\left(\mathrm{PO}_{4}\right)_{3} \mathrm{~F}$ \\
\hline Red chlorinated iron ore & $\mathrm{FePO}_{4} \cdot 2 \mathrm{H}_{2} \mathrm{O}$ \\
\hline Calcium mica & $\mathrm{Ca}\left(\mathrm{UO}_{2}\right)_{2}\left(\mathrm{PO}_{4}\right)_{2} \cdot 10-12 \mathrm{H}_{2} \mathrm{O}$ \\
\hline Turquoise & $\mathrm{CuAl}_{6}\left(\mathrm{PO}_{4}\right)_{4}(\mathrm{OH})_{8} \cdot 4 \mathrm{H}_{2} \mathrm{O}$ \\
\hline Chlorapatite & $\mathrm{Ca}_{5}\left(\mathrm{PO}_{4}\right)_{3} \mathrm{Cl}$ \\
\hline Aluminum phosphate stone & $\mathrm{AlPO}_{4} \cdot 2 \mathrm{H}_{2} \mathrm{O}$ \\
\hline Hydroxyapatite & $\mathrm{Ca} 5\left(\mathrm{PO}_{4}\right)_{3} \mathrm{OH}$ \\
\hline Monazite & $\left(\mathrm{REE}_{2}, \mathrm{Uh}_{2}\right)_{3} \mathrm{PO}_{4}$ \\
\hline Silver Star Stone & $\mathrm{Al}_{3}\left(\mathrm{PO}_{4}\right)_{2}(\mathrm{OH})_{3} \cdot 5 \mathrm{H}_{2} \mathrm{O}$ \\
\hline Phosphorous lead ore & $\mathrm{Pb}_{5}(\mathrm{PO})_{3} \mathrm{Cl}$ \\
\hline Yttrium ore & $\left(\mathrm{Y}, \mathrm{REE}_{\mathrm{PO}} \mathrm{PO}_{4}\right.$ \\
\hline
\end{tabular}

The raw materials for the production of phosphate fertilizer and phosphorus compounds are mostly phosphate rock, which is widely used in agriculture, chemical industry, medicine, food and other industrial sectors. According to statistics, $80 \%-90 \%$ of the world's phosphate rock is used to produce phosphate fertilizer, about $3 \%$ of the phosphate rock is used to produce feed additive, about $4 \%$ is used to produce detergent, and a small amount is used in chemical industry, light industry, national defense and other industries. With the rapid development of agriculture and the gradual increase of population, the demand of phosphate rock in the world and China is increasing (Figure 1). Since 2000, the consumption of phosphate rock in the world has been on the rise. In 2006, the total consumption of phosphate rock reached 46 million tons.

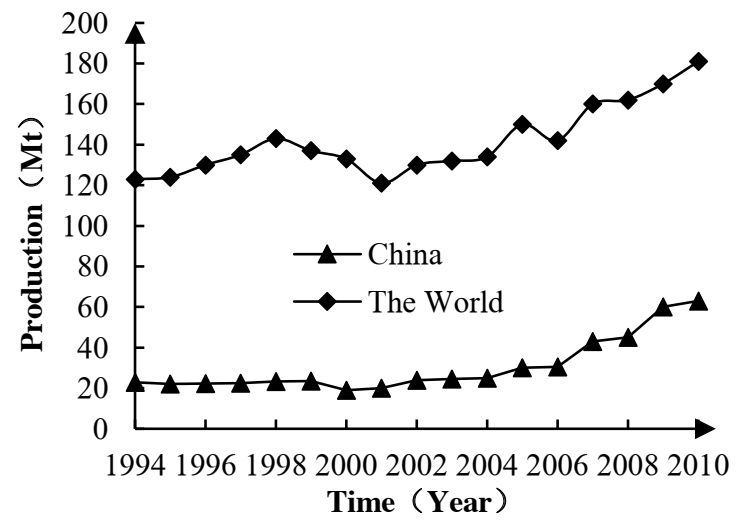

Fig. 1 production of phosphate rock resources in China and the world in recent 15 years ${ }^{[11]}$

\section{Activation of phosphate rock powder}

For low-grade phosphate rock, whether it is used as phosphate fertilizer in agriculture or as remediation materials to deal with heavy metal pollution in the environment, it needs to be activated to improve the content of available phosphorus. Traditional activation methods can be divided into three categories: physical method, chemical method and biological method. In recent years, many methods have been developed to activate phosphate ore powder, such as dissolving phosphate ore powder by phosphate solubilizing microorganisms, modifying organic active agents or surface active minerals acting on phosphate ore to release effective phosphorus.

\subsection{Phosphate dissolving microorganism dissolves phosphate ore powder}

Scakett et al ${ }^{[12]}$ first found in 1908 that some insoluble phosphate rock powder can be used by plants after being applied into the soil. There are mainly bacteria, fungi and actinomycetes in nature, which play an important role in the utilization of soil phosphorus. In fact, there are a large number of microorganisms in the soil and crop rhizosphere that can dissolve phosphate ore powder, which are collectively called phosphate dissolving bacteria. When the phosphate rock powder inoculated with phosphorus dissolving bacteria is applied to the soil, the phosphorus available for crops to absorb and use in the soil is significantly increased, and the biomass and yield of crops are increased. Wu Xiaoyan et al ${ }^{[13]}$. found that Soil Rhizosphere mixed bacteria had better decomposition ability for low-grade phosphate rock. The decomposition mechanism of inorganic phosphorus by microorganisms is mainly through the secretion of organic acids and heavy metal ions complexation, or to reduce the $\mathrm{pH}$ of soil, so as to promote the release of soluble phosphorus ${ }^{[14]}$.

\section{2 release of phosphate ore powder by activator}

The modification of active agent can promote the release of effective phosphorus in phosphate rock powder. When some complex organics are added to phosphate rock powder, organic acids can be produced in this process, which can promote the release of phosphorus. For example, $\operatorname{Badr}^{[15]}$ et al. Found that the soluble phosphorus content of phosphate rock powder modified by bagasse, furfural residue and other organics increased; the surface active mineral can promote the release of low-grade phosphate rock powder after the activation modification. It has been reported that zeolite and bentonite can promote the release of low-grade phosphate rock powder (montmorillonite) reacts fully with phosphate rock powder and reacts with $\mathrm{Ca}^{2+}$ in phosphate rock powder to activate phosphate rock powder so as to increase the content of available phosphorus $^{[16]}$.

\section{3 phosphorite powder activated by low molecular organic acid}

Low molecular organic acids are carboxylic compounds with molecular weight less than 500, such as acetic acid, oxalic acid, malic acid, citric acid, tartaric acid, etc., which are widely distributed in soil. There are a lot of free carboxyl and hydroxyl groups in low molecular organic acids, which have high activity and water solubility, chelation and coordination, and can effectively promote the release of effective phosphorus in insoluble phosphate. Liu Yonghong ${ }^{[17]}$ and others respectively used formic acid, acetic acid, oxalic acid and tartaric acid to activate phosphate rock powder in indoor culture. The results showed that the activation effect of phosphorus in phosphate rock powder increased with the increase of 
organic acid concentration, and the particle size of phosphate rock powder affected the activation effect. The smaller the particle, the better the activation effect. The activation effect of phosphate rock powder increased with the increase of liquid-solid ratio of activator and phosphate rock powder Liu Tingting et $\mathrm{al}^{[18]}$. showed that the activation effect of oxalic acid on low-grade phosphorite powder was the best when the concentration of oxalic acid was $40 \mathrm{mmol} / \mathrm{L}$; Gong Songgui et al ${ }^{[19]}$. studied the effect of oxalic acid, citric acid, tartaric acid and malic acid on the activation of inorganic phosphorus in red soil by indoor simulation test. The results showed that the ability of organic acid to activate soil phosphorus was citric acid $>$ tartaric acid $>$ malic acid at the same concentration, and Under the same acidity, aluminum phosphorus (a1-p) is the most active quantity, iron phosphorus (Fe-P) and calcium phosphorus ( $\mathrm{Ca}-\mathrm{P})$ are the second, and closed storage phosphorus (o-P) is the least; some studies have also shown that ${ }^{[20]}$ oxalic acid, citric acid, malic acid, etc. can promote the dissolution of insoluble phosphate and increase the content of phosphorus in soil solution by several times; Wang Guanghua et $\mathrm{al}^{[21]}$. have studied that the type and concentration of organic acid can activate phosphate ore powder With the change of organic acid concentration, the activation effect of phosphate rock powder is high or low.

Organic acids play an important role in a series of material cycles, such as soil mineral weathering, nutrient transformation and soil biological activity. Organic acids usually promote the release of phosphorus through dissolution, chelation and other functions. The release of organic acids to phosphorus is usually inseparable from its kind and concentration. The mechanism of organic acids promoting phosphorus release is as follows:

$$
\begin{gathered}
\mathrm{Ca}_{10}\left(\mathrm{PO}_{4}\right)_{6} \mathrm{~F}_{2}+12 \mathrm{H}^{+} \rightarrow 10 \mathrm{Ca}^{+}+6 \mathrm{H}_{2} \mathrm{PO}_{4}{ }^{-}+2 \mathrm{~F}^{-} \\
\mathrm{CaX}_{2} \cdot 3 \mathrm{Ca}(\mathrm{PO} 4)_{2}{ }^{+}+\text {Organic acid } \rightarrow \mathrm{PO}_{4}{ }^{3-}+\mathrm{Ca}- \\
\text { Organic acid }(\mathrm{X}=\mathrm{OH} \text { or } \mathrm{F}) \\
\mathrm{Al}(\mathrm{Fe}) \cdot\left(\mathrm{H}_{2} \mathrm{O}\right)_{3}(\mathrm{OH})_{2} \mathrm{H}_{2} \mathrm{PO}_{4}{ }^{+}+\text {Organic } \\
\text { acid } \rightarrow \mathrm{PO}_{4}{ }^{3-}+\mathrm{Al}(\mathrm{Fe})-\text { Organic acid }
\end{gathered}
$$

\section{Remediation effect and mechanism of phosphate rock powder and activated phosphate rock powder on heavy metals}

As early as 1981, the hydroxyapatite synthesized by Suzuki et al ${ }^{[22]}$ can effectively remove $\mathrm{Pb}^{2+}$ from water, and phosphorous materials are widely used as heavy metal repair agents. Phosphate remediation of heavy metals in soil is mainly through changing the form of heavy metals in the soil system, reducing its biological activity and availability, thus reducing its toxicity. $\mathrm{Hu}$ Jinhuai et $\mathrm{al}^{[23]}$. studied the remediation effect of different particle size and dosage of phosphate rock powder on heavy metals in soil. The research showed that the smaller the particle size of phosphate rock powder, the larger the dosage, the better the removal effect of heavy metals. Yin Fei et $\mathrm{al}^{[24]}$. showed that phosphate rock powder can significantly reduce the bioavailability of $\mathrm{Pb}, \mathrm{CD}, \mathrm{Cu}, \mathrm{Zn}$, as in soil. Zhang Lijie et $\mathrm{al}^{[25]}$. found that phosphate rock powder can reduce the recovery of heavy metals The content of $\mathrm{Cu}, \mathrm{Zn}, \mathrm{Pb}$ and $\mathrm{Cd}$ in the polluted soil was the best. Duan ran et $\mathrm{al}^{[26]}$. found that with the increase of the amount of oxalic acid and biochar, the $\mathrm{pH}$ in the soil increased gradually, and the bioavailability of CD and Ni decreased; Xu Xuehui ${ }^{[27]}$ found that the application of oxalic acid activated phosphate rock powder to the soil can effectively reduce the exchangeable CD in the soil, and the accumulation of $\mathrm{Cd}$ in the plant also decreased. Jiang Guanjie et al ${ }^{[28]}$. studied the passivation effect of oxalic acid activated phosphate rock powder on lead in Latosol. It was found that the mass fraction of exchangeable $\mathrm{Pb}$ in Latosol decreased significantly with the increase of phosphate rock powder application.

The reaction mechanism of phosphate to heavy metals is relatively complex, which is mainly determined by the properties of soil, components, anion and heavy metal. The main mechanisms include: co precipitation of phosphate and heavy metal ions after dissolution; surface complexation and adsorption of phosphate; co precipitation after dissolution of hydroxyapatite or ion exchange on the surface of phosphate ore.

\section{5 summary}

The problem of soil heavy metal pollution has been paid more and more attention. To solve the problem of soil heavy metal pollution has become an urgent need of ecological environment construction in China and even in the world. The research and development of high-efficiency remediation technology for heavy metal contaminated soil has been practically promoted and applied in practice, which is very important for the implementation of soil environmental control plan, adherence to the red line of cultivated land, and improvement of agricultural product quality and safety Meaning. China's phosphate rock resources are widely distributed, mostly used in agricultural phosphate fertilizer manufacturing, only a few used in industry, national defense, chemical industry, etc., but most of them are low-grade phosphate rock, and the phosphorus content is not fully used. In view of the rapid development of agriculture and the large-scale application of soil system remediation in China, it is of great practical significance to effectively apply low-grade phosphate rock to agricultural production and soil remediation engineering, which will help to improve agricultural production and realize the healthy recovery of heavy metal contaminated soil.

\section{reference:}

1. Cooper J, Lombardi R, Boardman D, et al. The future distribution and production of global phosphate rock reserves[J]. Resources, Conservation and Recycling, 2011, 57: 78-86.

2. Huang Zhiliang. Apatite mineral material.Beijing: Chemical Industry Press, 2008 
3. Brunner P H. Substance flow analysis as a decision support tool for phosphorus management[J]. Journal of Industrial Ecology, 2010, 14(6): 870-873.

4. Edwards A C, Walker R L, Maskell P, et al. Improving bioavailability of phosphate rock for organic farming[M]//Genetic Engineering, Biofertilisation, Soil Quality and Organic Farming. Springer, Dordrecht, 2010: 99-117.

5. Imarn M, Waqas R, Shaharoona B, et al. Effect of recycled and value- added organic waste on solubilization of rock phosphate in soil and its influence on maize growth[J]. International Journal of Agticulture and Biology, 2011,13(5):751-756.

6. Singh H,Reddy M.Sudhakara. Effect of inoculation with phosphate solubilizing fungus on growth and nutrient uptake of wheat and maize plants fertilized with rock phosphate in alkaline soils[J]. European Journal of Soil Biology,2011,47(1):30-34.

7. O'Day P A, Vlassopoulos D. Mineral-based amendments for remediation[J]. Elements, 2010, 6(6): 375-381.

8. Zhang $\mathrm{M}, \mathrm{Pu}$ J. Mineral materials as feasible amendments to stabilize heavy metals in polluted urban soils[J]. Journal of Environmental Sciences-China,2011,23(4):607-615.

9. Mignardi S, Corami A, Ferrini V. Evalation of the effectiveness of phosphate treatment for the remediation of mine waste soils contaminated with $\mathrm{Cd}, \mathrm{Cu}, \mathrm{Pb}$, and $\mathrm{Zn}[\mathrm{J}]$. Chemosphere, 2012,86:354-360.

10. Oelkers E H, Valsami-Jones E. Phosphate mineral reactivity and global sustainability[J]. Elements, 2008, 4(2): 83-87.

11. Liu Yonghong. Activation of phosphorite powder by organic acid and removal of copper from solution [D]. HuazhongAgriculturalUniversity, 2012.

12. Sackett W G, Patten A J, Brown C V. The solvent action of soil bacteria upon the insoluble phosphates of raw bone meal and natural raw rock phosphate[J]. Centralbl Bakteriol, 1908, 202: 688-703.

13. Wu Xiaoyan, Xiao Chunqiao, Chi Ruan. Effects of Particle Size and Pulp Density on Biosolubilization of Low-grade Rock Phosphate by Mixed Bacteria [J]. Mining and Metallurgical Engineering, 2015, 35(4): 87-90.

14. Huang Min, Wu Jinshui, Huang Qiaoyun, et al. Process in research on microbiological action of soil phosphorus [J]. Ecology and Environment, 2003, 12(3): 366-370.

15. Badr M A, Taalab A S. Release of phosphorus from rock phosphate through composting using organic materials and its effect on corn growth[J]. Bulletin of the National Research Centre (Cairo), 2005,30(6):629-638.

16. Li Yajuan, Qiu Huizhen. Activation of highly surface-activated minerals to phosphate rock and its effects on the growth of corn seedlings [J]. Journal of $\mathrm{Gan} \mathrm{Su}$ Agricultural University, 2005,
40(3):324-329.

17. Liu Yonghong, Jiang Guanjie, Cai Zhijian. et al. Activation of three kinds of low and medium grade phosphorite powder by low molecular weight organic acids $[\mathrm{C}] / /$ Sustainable utilization of soil resources and ecological environmental security: Proceedings of the second enlarged Council meeting and academic conference of the 11th Soil Society of China, 2009

18. Liu Tingting, Xu Guang, Xiao Chunqiao, et al. Activation and phosphorus releasing kinetics of low-grade powdered phosphate rock by organic acids [J]. Industrial Minerals \& Processing, 2017, 46(3): 1-4.

19. Gong Songgui, Wang Xingxiang, Zhang Taolin, et al Release of Inorganic Phosphorus from Red Soils Induced by Low Molecular Weight Organic Acids[J]. Acta Pedologica Sinica, 2010, 47(4): 692-697.

20. FoxTR, Comerford N B. Low-molecular-weight organic acids in selected forest soils of the southeastern USA[J]. Soil Science Society of America Journal, 1990, 54(4): 1139-1144.

21. Wang Guanghua, Zhou Derui, Yang Qian, et al. Effects of Low-Molecular-Weight Organic Acids on Release of Phosphorus from Rock Phosphate [J]. Journal of Agro-Environment Science, 2004, 23(1): 80-84.

22. Suzuki T, Hatsushika T, Hayakawa Y. Synthetic hydroxyapatites employed as inorganic cation-exchangers[J]. Journal of the Chemical Society, Faraday Transactions 1: Physical Chemistry in Condensed Phases, 1981, 77(5): 1059-1062.

23. $\mathrm{Hu}$ Qinhuai, Zhang Qing, Wang Huangping, et al. Passivation Mechanisms of Soil Heavy Metals Cd and $\mathrm{Pb}$ with Different Sizes of Phosphate Powder [J].Journal of Agricultural Resources and Environment, 2014, 31(2): 164-168.

24. Yin Fei, Wang Haijuan, Li Yanyan, et al. Remediation of Multiple Heavy Metal Polluted Soil Using Different Immobilizing Agents [J]. Journal of Agro-Environment Science, 2015 (3): 438-448.

25. Zhang Lijie, Zhang Yu, Liu Zenghui. Remediation of Soils Contaminated by Heavy Metals with Different Amelioration Materials [J]. Soils, 2009, 41(3): 420-424.

26. Duan Ran, $\mathrm{Hu}$ Hongqing, $\mathrm{Fu}$ Qingling, et al. Remediation of $\mathrm{Cd} / \mathrm{Ni}$ Contaminated Soil by Biochar and Oxalic Acid Activated Phosphate Rock [J]. Environmental Science, 2017, 38(11): 4836-4843.

27. Xu Xuehui, Jiang Guanjie, Hu Hongqing, et al. The Immobilization Effect of Oxalic Acid Activated Phosphate Rocks Applied to the Cd Contaminated Farmland Soil in Mining Area [J]. Journal of Agro-Environment Science, 2011, 30(10): 2005-2011.

28. Jiang Guanjie, Hu Hongqing, Zhang Junqing, et al. Immobilization effects of phosphate rock activated 
by oxalic acid on exogenouss lead in latosol [J].

Transactions of the Chinese Society of Agricultural

Engineering, 2012, 28(24): 205-213. 